\title{
Criminosos sexuais intrafamiliares: $O$ que há de errado com vocês?
}

\author{
Intra-family sex offenders: What is wrong with you? \\ Delincuentes sexuales intrafamiliares: ¿Qué te pasa?
}

Recebido: 21/06/2021 | Revisado: 27/06/2021 | Aceito: 30/06/2021 | Publicado: 13/07/2021

\author{
Carolina Ozelame Laner \\ ORCID: https://orcid.org/0000-0002-1129-0029 \\ Universidade de Passo Fundo, Brasil \\ E-mail: carolinalaner.psi@gmail.com \\ Silvana Alba Scortegagna \\ ORCID: http://orcid.org/0000-0002-5100-6459 \\ Universidade de Passo Fundo, Brasil \\ E-mail: silvanalba@upf.br
}

\begin{abstract}
Resumo
Este estudo teve como objetivo avaliar as características de personalidade de autores de violência sexual contra crianças e adolescentes. Metodologia: Participaram do estudo quatro indivíduos do sexo masculino, com idades entre 41 e 63 anos, condenados por crime sexual intrafamiliar, reclusos em um Presídio Estadual, localizado ao noroeste do estado do Rio Grande do Sul. Instrumentos: Ficha sociodemográfica, Inventário Fatorial de Personalidade (IFP-II), Neupsilin, Método de Zulliger e Técnica de Apercepção Temática (TAT). Resultados: Os traços de personalidade indicaram busca por afirmação pessoal, de poder e controle sobre os outros, dificuldades em lidar com impulsos, desejos de dominar e seduzir, vulnerabilidade no que se refere a aspectos internos, assim como percepção distorcida da realidade e falta de habilidades sociais. Considerações Finais: Os achados ideográficos são compatíveis com a literatura e podem ser úteis para amparar avaliações psicológicas e medidas de intervenção, além de instigarem o seguimento de estudos.
\end{abstract}

Palavras-chave: Traços de caráter; Fatores psicossociais; Agressões sexuais.

\begin{abstract}
This study aimed to evaluate personality characteristics of authors of sexual violence against children and adolescents. Methodology: Four male individuals, aged between 41 and 63, condemned for intrafamily sex crime participated in the study, prisoners in a state prison, located to the northwest of the state of Rio Grande do Sul. Instruments: Sociodemographic record, Factorial Personality Inventory (IFP-II), Neupsilin, Zulliger Method and Thematic Apperception Test (TAT). Results: Personality traits indicated a search for personal affirmation, power and control over others, difficulties in dealing with impulses, desires to dominate and seduce, vulnerability with regard to internal aspects, as well as distorted perception of reality and lack of social skills. Final Considerations: The ideographic findings are compatible with the literature and can be useful to support psychological evaluations and intervention measures, as well as instigating follow-up studies.
\end{abstract}

Keywords: Character traits; Psychosocial factors; Sex offenses.

\begin{abstract}
Resumen
Este estudio tuvo como objetivo evaluar las características de personalidad de los perpetradores de violencia sexual contra niños, niñas y adolescentes. Metodología: En el estudio participaron cuatro varones, con edades comprendidas entre 41 y 63 años, condenados por delitos sexuales intrafamiliares, presos en una Prisión Estatal, ubicada en el noroeste del estado de Rio Grande do Sul. IFP-II), Neupsilin, Zulliger Método y técnica de apercepción temática (TAT). Resultados: Los rasgos de personalidad indicaron la búsqueda de afirmación personal, poder y control sobre los demás, dificultades para lidiar con los impulsos, deseos de dominar y seducir, vulnerabilidad en los aspectos internos, así como percepción distorsionada de la realidad y falta de habilidades sociales. Consideraciones Finales: Los hallazgos ideográficos son compatibles con la literatura y pueden ser útiles para apoyar evaluaciones psicológicas y medidas de intervención, además de instigar el seguimiento de estudios.
\end{abstract}

Palabras clave: Rasgos de carácter; Factores psicosociales; Agresión sexual.

\section{Introdução}

É crescente o reconhecimento da necessidade de um tratamento mais abrangente à prevenção da violência sexual, para além das que buscam educar crianças para se protegerem da vitimização sexual. Pesquisas que buscam abordagens preventivas inovadoras contra a violência sexual são crescentes (Beier, 2018; Letourneau, Schaeffer, Bradshaw, \& Feder, 2017), com o a 
preocupação de abordar o início de comportamentos prejudiciais (Assini-Meytin, Fix \& Letourneau, 2020) e dar conta de implementar políticas mais abrangentes, incluindo determinantes psicossociais mais amplos.

Os complexos fatores de risco que cercam as condutas sexuais violentas envolvem características psicossociais e de personalidade. Condições psicossociais que podem aumentar o risco apontam para baixa escolaridade, ocupações em serviços informais (Casarin, Botelho \& Ribeiro, 2016; Scortegagna \&Amparo, 2013), abuso de substâncias, impulsividade, déficits nas habilidades sociais e no apego parental (Arslan, Demirkiran, Akcan, Zeren, \& Kokacya, 2016; Joyal Carpentier, \& Martin, 2016; Sullivan \& Sheehan, 2016).

Quanto aos resultados das investigações do funcionamento mental, as técnicas projetivas evidenciam especificidades na estrutura e dinâmica de personalidade de criminosos sexuais. Os perpetradores mostram problemas de autopercepção, baixa autoestima e prejuízos na autoimagem, na adequação perceptiva e no teste de realidade; déficit na capacidade de estabelecer vínculos, de empatia e na estabilidade das identificações (Scortegagna \&Amparo, 2013), insuficiência de recursos para adaptação ao ambiente, estilo relacional passivo e imaturo, tendência acentuada para fantasiar, o que contribui para percepção distorcida da realidade (Etcheverria, 2009); impulsividade e busca pela satisfação imediata de suas necessidades (Casarin et al., 2016).

Com o uso de testes de autorrelato, as pesquisas indicam que criminosos sexuais apresentam tendências manipuladoras e impulsividade, envolvimento com vários crimes (Davis, 2017; Flores-Mendoza, 2008; Hackett, Masson, Balfe \& Phillips, 2013), baixa autoestima e narcisismo explícitos (Pettersen, Nunes, Kostiuk, Jung \& Atlas, 2016; Sullivan \& Sheehan, 2016), sintomas depressivos, déficit de empatia, de interação social (Wielinga, Margeotes \& Olver, 2019) e distorções cognitivas (Rodrígues \& Pérez, 2016; Ward \& Keenan, 1999; Wielinga et al., 2019). Comumente percebem-se como vulneráveis, incompreendidos por outros adultos, com direito a sexo; se identificam emocionalmente com crianças, acreditam que as elas representam uma opção de intimidade, que as relações sexuais são mutuamente benéficas (Heffernan \& Ward, 2015; Ward \& Keenan, 1999) e que os desejos das crianças precisam ser satisfeitos (Sullivan \& Sheehan, 2016), valendo-se assim das vantagens da proximidade e intimidade com a vítima, quando a violência sexual é perpetrada pelo pai ou padrasto (Hackett et al., 2015; Scortegagna \& Villemor-Amaral, 2009; Sullivan \& Sheehan, 2016; South Eastern Casa, 2017).

Outros estudos mostram que criminosos sexuais apresentam déficits cognitivos (Hackett et al., 2015; Heffernan \& Ward, 2015; Katsuta \& Hazama, 2016; Winder, Gough \& Seymour-Smith, 2015), sentimentos de solidão e falta de vínculo emocional com o conjugue, manipulação, sedução e persuasão (Nascimento, 2017), além do desejo de enganar, dominar, controlar (FloresMendoza, 2008) e impulsividade (Joyal et al., 2016). Tais características podem estar relacionadas a hipersexualidade (Davis, 2017), a violência sexual em crianças e necessitam serem mapeadas para que possam dar suporte as avaliações e ao desenvolvimento de medidas de intervenção.

Como pode ser observado criminosos sexuais têm sido descritos de modo extensivamente heterogêneo em suas características psicológicas, sendo a literatura brasileira escassa, insuficiente e inconclusiva. Diante desta realidade que cerca este grave problema de saúde pública, da necessidade de se compreender os fatores psicossociais vinculados ao crime, este estudo buscou avaliar a personalidade de autores de violência sexual perpetrada contra crianças e adolescentes.

\section{Metodologia}

Trata-se de uma pesquisa de natureza qualitativa e exploratória. A abordagem qualitativa se destina a desenvolver teorias, utilizar estudos de casos e compreender a experiência subjetiva. Um estudo exploratório caracteriza-se por permitir o pesquisador elaborar um parecer mais aproximado do que se pesquisa, principalmente, quando se trata de um tema pouco investigado e há mais flexibilidade em relação ao planejamento (MINAYO, 2012). Quanto ao método de investigação, utilizouse o estudo de caso, com o objetivo de coletar dados detalhados e sistemáticos sobre um fenômeno complexo (YIN, 2015). 


\subsection{Participantes}

Participaram do estudo quatro homens (denominados de S1, S2, S3, S4), com idade entre 41 a 63 anos, autores de violência sexual intrafamiliar perpetrada contra crianças e adolescentes. A amostra foi procedente de um Presídio Estadual, localizado ao noroeste do estado do Rio Grande do Sul.

\subsection{Instrumentos}

a) Ficha sociodemográfica com o objetivo de coletar dados como idade, estado civil, escolaridade, profissão, tempo de encarceramento e características psicossociais relacionadas a violência.

b) Instrumento de Avaliação Neuropsicológica Breve (NEUPSILIN; Fonseca, Salles \& Parente, 2009): Descreve o desenvolvimento neuropsicológico ao longo do ciclo vital por meio da avaliação de 8 funções cognitivas: 1) Orientação Têmporo-Espacial; 2) Atenção Concentrada; 3) Percepção Visual;4) Habilidades Aritméticas; 5) Linguagem Oral e Escrita; 6) Memória Verbal e Visual; 7) Praxias; 8) Funções Executivas. No presente estudo, foram utilizados os quatro subtestes de avaliação da percepção: 1) Verificação de igualdades e diferenças; 2) Heminegligência visual; 3) Percepção de Faces; 4) Reconhecimento de Faces.

c) Inventário Fatorial de Personalidade (IFP-II; Leme, Rabelo \& Alves, 2013): Avalia características de personalidade por meio de 100 itens utilizando afirmativas em uma escala do tipo Likert, que varia de 1 (nada característico) até 7 (totalmente característico). Esses itens avaliam 13 características/necessidades ou motivos (psicológicos), configurando três grupos de segunda ordem: 1) Necessidade de Afeto (Afiliação, Assistência, Afago, Intracepção, Deferência e Mudança); 2) Necessidade de Organização (Ordem, Desempenho e Persistência) e; 3) Necessidade de Controle e Oposição (Exibição, Agressão, Autonomia e Dominância).

d) Teste de Zulliger no Sistema Compreensivo (ZSC; Villemor-Amaral \& Primi, 2009) avalia características de personalidade, composto de três pranchas com manchas de tinta. Neste estudo foi utilizada aplicação R-otimizada, proposta no Sistema de Avaliação por Performance no Rorschach (R-PAS; Meyer, Viglione \& Mihura, 2016). Sua função é limitar a variação entre protocolos quanto ao número de respostas, evitando que este aspecto afete negativamente os resultados encontrados. Solicitou-se a emissão de três a cinco respostas por cartão.

e) Teste de Apercepção Temática (TAT; Murray, 2005): Avalia características de personalidade, constituído de pranchas com estímulos que abrangem situações humanas clássicas. Em sua aplicação o sujeito deve contar uma história sobre cada uma das pranchas. Considerando o objetivo proposto por este estudo, foram aplicadas três pranchas: a) Prancha 4 avalia conflitos nas relações heterossexuais, conflitos de controle de impulsos e conflitos amorosos; b) Prancha 6MF, investiga relação homemmulher; c) Prancha 8RH, avalia aspectos de agressividade, vivências de castração e destruição.

\subsection{Procedimentos}

Todos os cuidados éticos inerentes à pesquisa científica foram conduzidos. O projeto foi aprovado pelo Comitê de Ética em Pesquisa (CEP) de uma Universidade e recebeu aprovação sob parecer de número 2.740.467. Os participantes do estudo foram encaminhados para avaliação pelo responsável pelo setor penitenciário e todos assinaram o Termo de Consentimento Livre e Esclarecido (TCLE). Os testes foram respondidos individualmente, em duas sessões de 40 minutos cada, nas 
dependências da instituição carcerária. Na primeira sessão, os participantes responderam a ficha sociodemográfica, ao Neupsilin e ao IFP-II. Na segunda sessão responderam ao ZSC Aplicação R-Otimizada e ao TAT.

\subsection{Análise dos dados}

Para a correção e interpretação dos resultados do Neupsilin, foram calculados o total de acertos de cada subteste e o escore composto de percepção com a soma dos acertos de todos os subtestes. Os escores brutos foram transformados em Escore $\mathrm{Z}$ padronizado e considerado déficit $\mathrm{Z}$ menor/igual à -1,5. O IFP considera traços marcantes de personalidade escores abaixo do percentil 30 e acima do percentil 70. Os escores dos protocolos do ZSC foram confrontados com indicadores de referência nacional da população de não-pacientes $(\mathrm{N}=220)$. Para interpretação dos resultados do TAT foram utilizados os conteúdos referentes às relações do sujeito com personagens das histórias, o meio e as necessidades expressas nos conteúdos relatados.

\section{Resultados}

Primeiramente serão apresentados os dados sociodemográficos e na sequência, os resultados do Neupsilin, IFP-II, ZSC e TAT. Os dados sociodemográficos referentes à faixa etária dos abusadores, das vítimas quando da ocorrência do abuso, grau de parentesco do abusador em relação à vítima e outros aspectos relacionados as características do agressor podem ser visualizados na Tabela 1 .

Tabela 1. Descrição dos dados sociodemográficos e psicossociais dos participantes do estudo.

\begin{tabular}{|c|c|c|c|c|}
\hline & S1 & $\mathrm{S} 2$ & S3 & S4 \\
\hline Idade abusador & 41 anos & 54 anos & 63 anos & 43 anos \\
\hline Estado conjugal & União Estável & União Estável & Divorciado & Divorciado \\
\hline Escolaridade & $\begin{array}{l}\text { Ens. Fundamental } \\
\text { incompleto }\end{array}$ & $\begin{array}{l}\text { Ens. Fundamental } \\
\text { incompleto }\end{array}$ & $\begin{array}{l}\text { Ens. Médio } \\
\text { incompleto }\end{array}$ & $\begin{array}{l}\text { Ens. Fundamental } \\
\text { incompleto }\end{array}$ \\
\hline Uso de drogas & Não & Sim & Sim & Não \\
\hline Profissão & Serviços gerais & Pintor & Motorista & Comerciante \\
\hline Pena & 32 anos & 12 anos & 9 anos & 12 anos \\
\hline $\begin{array}{c}\text { Tempo de } \\
\text { encarceramento }\end{array}$ & 1 ano e 8 meses & 2 anos & 7 meses & 1 ano e 7 meses \\
\hline Acusação & Abuso sexual & Abuso sexual & Abuso sexual & $\begin{array}{l}\text { Abuso sexual, porte de } \\
\text { arma, Maria da Penha }\end{array}$ \\
\hline Vítima & Enteada & Sobrinho neto & Neta do cônjuge & Filha \\
\hline Idade da vítima & 13 anos & 7 anos & 8 anos & 17 anos \\
\hline Situação de moradia & Residia com a vítima & $\begin{array}{l}\text { Residia com a } \\
\text { vítima }\end{array}$ & $\begin{array}{c}\text { Não residia com a } \\
\text { vítima }\end{array}$ & Residia com a vítima \\
\hline $\begin{array}{c}\text { Familiares } \\
\text { transgressores }\end{array}$ & Irmão & Não & Não & Pai \\
\hline $\begin{array}{c}\text { Outros } \\
\text { processos/prisões }\end{array}$ & Lesões e brigas & Não & Embriagues & Desacato \\
\hline
\end{tabular}

Fonte: Autores.

Observa-se na Tabela 1 que os agressores tinham média de idade de 50,1 anos (DP=8,87), baixa escolaridade, abandono escolar precoce, ocupações informais e $50 \%(n=2)$ possuíam familiares que cometeram algum delito. A maior parte deles havia sido encarcerado em outras circunstâncias, por crimes como lesões e brigas, embriagues e desacato. O tempo médio estimado de pena era de 16,25 anos $(\mathrm{DP}=9,17)$ e o tempo máximo de encarceramento, quando da realização deste estudo, era de dois anos. 
Três das vítimas eram do sexo feminino e um do sexo masculino, com média de idade foi de 11,5 anos (DP=4,02). A violência sexual ocorreu no âmbito intrafamiliar, os abusadores mantinham contato próximo com a vítima, residiam na mesma casa ou proximamente. Os resultados sociodemográficos corroboram a literatura precedente ao demonstrarem que os abusadores sexuais possuem baixa escolaridade, ocupações em serviços informais (Casarin et al.,2016; Scortegagna \& Amparo, 2013), e já foram condenados por outros crimes (Hackett et al., 2013).

Os dados relacionados as vítimas de violência sexual, indicam que a violência foi perpetrada pelo próprio pai ou o padrasto, que mantinha vínculo afetivo e de confiança com a mesma, corroborando estudos anteriores (Hackett et al., 2015; Scortegagna \& Villemor-Amaral, 2009).

$\mathrm{Na}$ avaliação neuropsicológica obtida com o Neupsilin, os criminosos apresentaram um total na percepção total de 1, 0,24, - -0,61 e -1,36. Na tarefa de Heminegligência Visual (riscar todos os traços em uma folha), por exemplo, caracterizada geralmente pela ausência de resposta do indivíduo a estímulos sensoriais, táteis, visuais e/ou auditivos, todos os participantes obtiveram pontuação máxima, não apresentando alterações. Na sequência, a Figura1 expõe as características de personalidade autorrelatadas pelos participantes do estudo verificadas por meio do IFP-II.

Figura 1.Descrição dos escores obtidos com o IFP-II pelos participantes do estudo.

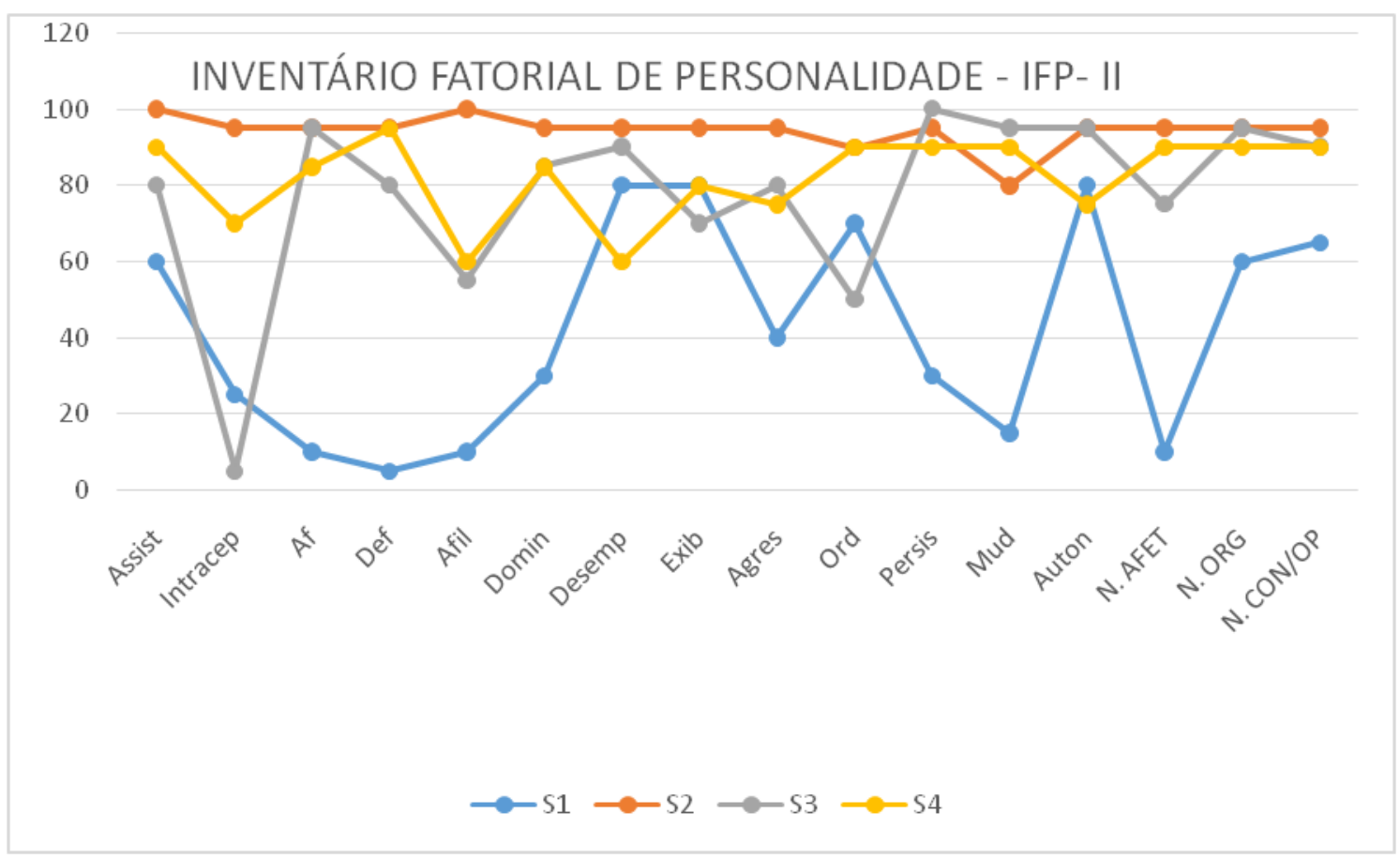

Fonte: Autores.

Verifica-se na Figura 1 que os participantes $(n=3)$ apresentaram indicadores elevados no agrupamento das Necessidades Afetivas, de Organização e de de Controle e Oposição. O agrupamento das necessidades afetivas, acima da média sugere: a) Assistência (S2;S3;S4) presença de desejos e sentimentos de piedade, compaixão e ternura, pelos quais há desejos de gratificar as necessidades de um sujeito indefeso; b) Afago (S2,S3,S4), busca de apoio e proteção, desejos de ser amado, perdoado e consolado; presença de ansiedade e sentimentos de abandono, insegurança e desespero; c) Deferência (S2, S3, S4) sugere respeito, admiração e deferência as pessoas, desejo de admirar e dar suporte a um superior; d) Mudança (S2, S3, S4) indica prazer por novidades, aventuras, de desligar-se do que é rotineiro. Necessidades Afetivas, abaixo da média, sugerem: a) Intracepção (S1, S3) pouco uso da fantasia e imaginação, falta de consideração às intenções dos outros. 
Elevados escores no agrupamento das Necessidade de Organização, propõem características de personalidade como: a) Persistência (S2, S3, S4) tendência a encerrar um trabalho iniciado, obsessão pelo resultado final; b) Desempenho (S2, S3) desejo de dominar, manipular objetos, pessoas e ideias; de fazer coisas independentemente e de se sobressair.

No agrupamento das Necessidade de Controle e Oposição, a amostra denotou características acima da média em: a) Agressão (S2, S3, S4) anseio de atacar e injuriar os outros, por meio de atitudes opositoras, censura e ridicularização; sentimentos de raiva, irritação e ódio; b) Exibição (S1, S2, S4), desejo de impressionar, fascinar as pessoas; c) Autonomia (S1, S2, S3, S4), pressupõe resistir à coerção e à oposição, de agir independente e livremente seguindo os impulsos; desafiar qualquer convenção, dificuldades em executar tarefas impostas pela autoridade; dificuldades para controlar sentimentos negativos, especialmente relativos à frustração; d) Dominância (S2, S3, S4), sentimentos de autoconfiança e desejo de controlar os outros, influenciar ou dirigir o comportamento deles por meio de sugestão, sedução, persuasão ou comando. A seguir, a Tabela 2 apresenta os dados obtidos com o ZSC comparados com as expectativas normativas do grupo de não pacientes (Franco, Cardoso, Villemor-Amaral \& Primi, 2009).

Tabela 2. Descrição das variáveis do ZSC nos e dados normativos (N=220).

\begin{tabular}{|c|c|c|c|c|c|c|}
\hline \multirow[t]{2}{*}{ Variáveis do ZSC } & \multicolumn{4}{|c|}{ Participantes } & \multicolumn{2}{|c|}{ Normas } \\
\hline & $\mathrm{S} 1$ & $\mathrm{~S} 2$ & S3 & $\mathrm{S} 4$ & $\mathrm{M}$ & DP \\
\hline MOR & $1 \uparrow$ & 0 & $1 \uparrow$ & $2 \uparrow$ & 0,3 & 0,5 \\
\hline $\mathrm{XA} \%$ & 77,7 & 90 & 55,5 & 60 & 73,0 & 21,0 \\
\hline$X-\%$ & 22,2 & 10 & $44,4 \uparrow$ & $40 \uparrow$ & 21,0 & 15,9 \\
\hline $\mathrm{X}+\%$ & $22,2 \downarrow$ & 50 & $22,2 \downarrow$ & 30 & 47,2 & 21,3 \\
\hline $\mathrm{Xu} \ddot{ } \cdot \%$ & 33,3 & 40 & 33,3 & 30 & 25,7 & 17,8 \\
\hline $\mathrm{a}: \mathrm{p}$ & $0: 0$ & $1: 0$ & $0: 1$ & $2: 3$ & 0,5 & 1,6 \\
\hline Ma:Mp & $1: 0$ & $1: 0$ & $0: 1$ & $2: 3$ & 0,4 & 0,9 \\
\hline $\mathrm{W}: \mathrm{D}: \mathrm{Dd}$ & $0: 7: 2$ & $0: 7: 2$ & $0: 9: 1$ & $3: 7: 0$ & - & - \\
\hline $\mathrm{W}: \mathrm{M}$ & $0: 1$ & $0: 1$ & $0: 1$ & $3: 5$ & 0,4 & 1,5 \\
\hline DQ+ & $2 \uparrow$ & $2 \uparrow$ & 0 & $2 \uparrow$ & 0,3 & 0,5 \\
\hline WDA & 66,6 & 80 & $33,3 \downarrow$ & 60 & 65,9 & 20,2 \\
\hline Sum V & 0 & 1 & 0 & 0 & 0,1 & 0,4 \\
\hline $3 r+(2)$ & 0,1 & 0,4 & 0,3 & 0,1 & 2,1 & 1,9 \\
\hline$A n+X y$ & 0 & 0 & 0 & 1 & 0,6 & 0,8 \\
\hline $\mathrm{H}$ & 1 & 1 & 0 & 0 & 0,8 & 1,0 \\
\hline (H) & 0 & $1 \uparrow$ & $1 \uparrow$ & 0 & 0,3 & 0,6 \\
\hline $\mathrm{Hd}$ & 0 & 1 & 0 & 0 & 0,4 & 0,8 \\
\hline$(\mathrm{Hd})$ & 0 & 0 & 0 & 0 & 0,2 & 0,4 \\
\hline $\mathrm{H}:(\mathrm{H})+(\mathrm{Hd}+(\mathrm{Hd})$ & $1: 0$ & $1: 2$ & $0: 1$ & $0: 0$ & $-0,1$ & 1,5 \\
\hline S- & $3 \uparrow$ & 2 & $3 \uparrow$ & 2 & 1,4 & 1,2 \\
\hline $\mathrm{FC}: \mathrm{CF}+\mathrm{C}$ & $0: 1$ & $2: 0$ & $2: 1$ & $1: 0$ & 0 & 0 \\
\hline Sum C':WSumC & $1: 1$ & $0: 1$ & $0: 1$ & $0: 0,5$ & $-0,1$ & 1,1 \\
\hline Afr & 0,5 & 0,5 & $1,3 \uparrow$ & 0,4 & 0,5 & 0,2 \\
\hline Blends:R & 0,2 & 0,2 & 0,1 & $0,7 \uparrow$ & 0,2 & 0,2 \\
\hline $\mathrm{AG}$ & $1 \uparrow$ & 0 & 0 & $1 \uparrow$ & 0,3 & 0,5 \\
\hline Sum T & 0 & 0 & 0 & 0 & 0,0 & 0,2 \\
\hline Sum H & 1 & $3 \uparrow$ & 1 & 0 & 1,7 & 1,5 \\
\hline PER & $1 \uparrow$ & 0 & 0 & 0 & 0,2 & 0,7 \\
\hline Isolamento & 0 & $5 \uparrow$ & $4 \uparrow$ & 2 & 1,3 & 1,6 \\
\hline
\end{tabular}

Nota. $\uparrow$ aumento; $\downarrow$ diminuição. Fonte: Autores. 
Na Tabela 2 os indicadores de processamento emocional/afetivo inicialmente sugerem que em três dos participantes (S2, S3 e S4), pode haver certa modulação das descargas emocionais, que as experiências afetivas podem estar controladas/direcionadas por elementos cognitivos $(\mathrm{FC}>\mathrm{CF}+\mathrm{C})$. Entretanto, como a diferença na proporção dos resultados é marginal, esse dado deve ser confirmado ou não com outros testes. Há indícios em três dos participantes (S1, S2 e S3), de um estilo mais inconsistente no uso do afeto e da ideação de modo mais aleatório ( $\mathrm{M}=\mathrm{WSumC})$, comumente encontrado em pessoas imprevisíveis. Na sequência, as tabelas 4, 5 e 6 apresentam os resultados encontrados com o uso do TAT. Especificamente a Tabela 3 apresenta as narrativas obtidas na prancha 4.

Tabela 3. Descrição das narrativas dos participantes do estudo na prancha 4 TAT.

\begin{tabular}{|c|c|}
\hline & PRANCHA 4 \\
\hline S1 & $\begin{array}{l}\text { Deve ser um fim de relacionamento. Ele quer ir embora, ela não quer deixar. Ela está segurando ele para não } \\
\text { brigar com alguém também, por ciúmes dela. Ciúmes dela do que? Deve ter chegado alguém ali, ele deve ter } \\
\text { ficado com ciúmes e foi brigar. O que aconteceu antes? eles estavam namorando e chegou o amante. O que } \\
\text { ele está pensando? Que foi traído. Como ele está se sentindo? Com ódio. Como termina? Ele briga com o } \\
\text { amante e ele fica junto com a mulher de novo Título? O amor proibido. }\end{array}$ \\
\hline S2 & $\begin{array}{l}\text { Ele está falando algo para ela e mostrando, como se ele quisesse brigar com alguém, mostrando algo esquisito } \\
\text { e ela não quer que ele olhe porque ela está segurando. Ele está bravo. O que aconteceu antes? Eles deveriam } \\
\text { estar em uma festa, ou teatro, onde deveriam ter mais pessoas. Motivo da briga? Ciúmes dela, porque ela é } \\
\text { bonita, alguém olhou para ela. O que ele está sentindo? Raiva, ódio, quer se vingar. Como termina? Eles indo } \\
\text { para casa, se controlando, ela acalmou ele. Título? O amor sem correspondência. }\end{array}$ \\
\hline S3 & $\begin{array}{l}\text { Um casal. Imagem de uma pessoa sofrida. Ela está dando afeto a ele. Parece que ela é esposa dele, consolando } \\
\text { a tristeza dele, para ele se acalmar. Como se ela estivesse contando algo a ele, algo do filho, que fez algo } \\
\text { errado, para ele escutar. Fez o que de errado? O filho é de menor, saiu beber, fumar, aprontar. O que } \\
\text { aconteceu antes? O filho saiu para fora e quando chegou, contou para a mãe e a mãe contou para o pai. O que } \\
\text { ele está pensando? Em outras coisas, ir beber. O que ele está sentindo? Culpado, porque não está dando } \\
\text { atenção. Como termina? Mais tarde ele vai dar um carinho para o filho. Título? Um erro. }\end{array}$ \\
\hline S4 & $\begin{array}{l}\text { Conheci essa pessoa, tivemos uma vida boa, apesar das adversidades da vida, mas como nos conhecemos } \\
\text { melhor, essa pessoa parecia ser, apesar de uma menina linda, dentro do seu coração existia também coisas } \\
\text { ruins, na vida de nós dois. O que está acontecendo agora? Vejo que eu conheci agora ela, realmente, o que } \\
\text { ela é e ela se arrepende de tudo o que fez de errado. A amargura já tomou conta e a certeza que quer outra } \\
\text { vida amorosa. Do que se arrepende? Brigas, mentiras, por ser amarga. O que aconteceu antes? Mentia que } \\
\text { queria dar filhos a ele, que o amava de todo o coração, mas depois não era real. O que ele estava pensando? } \\
\text { Que foi enganado. Como termina? Um para cada lado, a decisão já está tomada. Título? Valoriza enquanto } \\
\text { tem. }\end{array}$ \\
\hline
\end{tabular}

Fonte: Autores.

Na Tabela 3, verifica-se conflitos nas relações heterossexuais, conflitos de controle de impulsos e conflitos amorosos. Observa-se que os heróis das histórias são homens, envolvidos em relacionamentos com mulheres em que predominam sentimentos de raiva, ciúmes, agressão, ódio e amargura, por parte dos protagonistas. Com auxílio das forças do ambiente ou de pessoas, que buscam conter os impulsos do personagem, prevalece a superação dos conflitos. Entre os temas comuns das histórias estão: brigas, conflitos em relacionamentos, mentiras e vingança. A tabela 4 apresenta as respostas obtidas na prancha $6 \mathrm{MF}$ do TAT. 
Tabela 4. Descrição das narrativas dos participantes do estudo na prancha 6 MF do TAT.

\section{PRANCHA 6}

S1 Uma mulher assustada. Um homem conversando com ela. Ele está tentando seduzir ela. O que aconteceu antes? Ela estava se maquiando e ele chegou. O que ele está pensando? Que ela tem que ser a mulher dele. O que ele está sentindo? Atração por ela. O que ela está sentindo? Medo. Como termina? Acaba aceitando deixá-la em paz. Título? Sedução

S2 Ele deve estar falando algo para ela, que ela não goste, ela está olhando com uma cara de espanto. Ela não está concordando com o que ele está falando. Ele falou que ela é bonita e ela não gostou dele, do elogio, da maneira que ele falou. O que aconteceu antes? Eles estavam em um lugar público, café, e eles se encontraram e ela não gostou da atitude dele. O que ele está sentindo? Raiva dela. O que ele está pensando? Que ela não gostou do que ele falou. Como termina? Cada um para um lado. Bem, não termina. Título? Ódio

S3 Ele chegou fumando, com o rosto embriagado e falou com ela e pelo o que a gente sente, ela só virou e não gostou. Ela não gosta que ele fume, só olhou para ele de lado. Ele falou com ela, ela não deu muita conversa. $O$ que aconteceu antes? Ele saiu beber para fora e chegou assim e ela não gostou. Como era o relacionamento deles? Ruim. O que ele está sentindo? Uma maldade, algo ruim. O que ele está pensando? Em conquistar ela. Como termina? Eles não tendo mais afeto um pelo outro, ficam separados. Título? Erros

S4 Estamos de meia idade. Nos damos bem. Somos felizes. Temos filhos e netos. Depois que a mulher, com o passar do tempo, resfriou o seu amor, seu esposo pega e começa a olhar para outros lados. Nos tempos da sua robustez, seu rosto não tinha marcas (dela) e começa a ver jovens lindas e decide arrumar uma amante e a esposa agora diz - "porque que você fez isso, tanto tempo que estamos juntos" - aí ele diz - "você sabe que você é a mulher da minha vida, prometi que iríamos ficar velhinhos juntos e é isso que eu quero" -. Ela pergunta - "então porque você me traiu?" - "porque você não tem mais olhos para mim, fica só cuidando dos netos e afazeres". O que aconteceu antes? Ela começou a olhar para os netos, cuidá-los, ele apesar de amá-los, queria ter um momento com ela a sós. O que ele estava pensando? Porque você deixou isso acontecer no nosso meio, você não colocava mais aquela roupa linda, apesar dos anos, você é o amor da minha vida. Como termina? Eles juntos. Título? Nunca é tarde para ser feliz.

Fonte: Autores.

Na Tabela 4, conforme as narrativas sobre a relação homem-mulher, vê-se que os heróis das histórias são homens envolvidos em um relacionamento com mulheres. Os sentimentos dos protagonistas são predominantemente de raiva e amor e os desejos ou necessidades voltam-se para a posse do outro. Entre as forças do ambiente e desfecho da história, observa-se que o ambiente age contra os desejos e impulsos do protagonista, não os satisfazendo. As histórias centram-se em temáticas de conquista do sexo oposto, conflitos e traição. A Tabela 5 apresenta as respostas obtidas na prancha 8RH do TAT. 
Tabela 5. Descrição das narrativas dos participantes do estudo na prancha 8RH do TAT.

\section{Prancha 8}

S1 Uma guerra. Um homem leva um tiro, o seu amigo está tentando tirar a bala da barriga dele, ele acaba morrendo. $O$ que aconteceu antes? Brigou com alguém, tomou um tiro, o amigo tenta tirar a bala da barriga. Motivo da briga? Por causa de bebida. O que ele está pensando? Que o amigo vai salvar. O que ele está sentindo? Dor. O que os amigos estão pensando? Na salvação dele. Como termina? Na morte. Título? A morte.

S2 Aqui deve ser uma briga, uns com uma espingarda, outros com uma faca. Estão operando, tirando a bala. Estão querendo salvar um que está baleado. A faca não é para matar, deve ser para tirar uma bala do corpo, que o feriu e caiu no chão. Seus amigos e colegas estão tentando salvar ele. O que aconteceu antes? Uma briga. Motivo da briga? Político. Como estavam se sentindo? Com pressa para salvar o ferido. O que estavam pensando? Que vão tentar salvar ele. Como termina? Eles conseguindo salvar ele. Título? A sobrevivência.

S3 Eles brigam e o outro caiu e o cara pegou uma faca para estrangular o outro. Parece que esse aqui seja uma autoridade, só que ele não está vendo o que o outro está fazendo atrás e com certeza eles estão embriagados, os que estão deitados e os outros. Estão fazendo coisa errada. O que aconteceu antes? Estavam em uma boa, todos bebendo e depois se embriagaram e brigaram. O que ele está pensando? Que ia morrer. O que ele está sentindo? Dor. O que os outros estão sentindo? Felicidade de um estar ajudando o outro a matar. Como termina? Confusão total. O guri não morre. Depois que sai do álcool, vai para casa. Eles o deixam ferido. Título? Maldade.

S4 Esse cara de gravata estava indo na igreja, se deparou com um assalto. Resolveu reagir, onde ele foi surpreendido e os elementos acabaram tirando a sua vida. A vítima é que está deitado e o pastor pensa o que poderia fazer vendo esse sinistro, sendo que ele tinha essa arma do lado dela, mas não é dele. Está no alcance dele para fazer o bem ou deixá-los de lado. O que aconteceu antes? Esse irmão passava seguido nessa rua, apesar de escura, era o caminho mais seguro para o seu destino. Então via esses dois elementos, mas nunca pensava que seriam pessoas capazes de tirar a vida de alguém. O que ele está pensando? Se ele não estivesse reagido, não teria acontecido isso. O que ele está sentindo? Muita dor. Como termina? A vítima morre, o pastor fica um pouco traumatizado e os dois elementos não são mais reconhecidos, pois estava escuro para ver seus rostos. Título? Não reaja se não tiver total controle da situação.

Fonte: Autores.

Verifica-se na Ttabela 5 aspectos de agressividade, vivências de castração e destruição. As verbalizações mostram que os heróis das histórias do TAT são homens que estão machucados. Os sentimentos dos protagonistas são de sofrimento, dor, tensão e necessidade de ajuda. Os finais das histórias divergem entre os participantes. Enquanto S3 e S2 propõem desfechos positivos em suas histórias, S1 e S4 escolhem desfechos negativos. Entre os temas das histórias narradas, estão: briga, agressão e ferimento.

\section{Discussão}

Ao observar os resultados, é possível delinear alguns dos principais fatores de personalidade e das necessidades psicológicas dos participantes da pesquisa. Os dados sociodemográficos apontam baixa escolaridade, abandono escolar precoce e ocupações informais. Encarceramento por outras circunstâncias, demais crimes e envolvimento de familiares em atos de delinquências, são aspectos evidentes.

Estes resultados confirmam estudos prévios que certificam que a violência sexual intrafamiliar apresenta vantagens quanto ao domínio da relação do adulto sobre a criança, quando comparado a ocorrência de violência sexual em outros contextos (Sullivan \& Sheehan, 2016; South Eastern Casa, 2017). Características de personalidade como dominância e desempenho sugerem desejo de exercer domínio, controlar, enganar (Flores-Mendoza, 2008) e manipular os outros, dirigir o comportamento por meio da sedução e persuasão, comumente encontradas no contexto de abuso. Nascimento (2017) explicita que a relação entre abusador e vítima é caracterizada pela sedução da criança e a conquista de sua confiança, enquanto Heffernan e Ward (2015) referem que a manipulação da criança pode gerar prazer e ímpeto no abusador, além do prazer sexual.

Os resultados do NEUPSIILIN mostram que os sujeitos avaliados não apresentaram alterações neurológicas. No subteste percepção de faces, uma atividade de relevância no cotidiano do ser humano, a maior parte dos sujeitos apresentou pontuações baixas, principalmente S2, o que pode indicar falhas perceptivas que acarretam distorções cognitivas. Tais distorções 
são amplamente evidenciadas em perpetradores sexuais nas suas atitudes e crenças violadoras de normas, nas fantasias e racionalizações e nas justificativas para seus atos criminosos como, por exemplo, o entendimento de crianças como seres sexuais, capazes de escolher fazer sexo e que isso não é prejudicial, em contrário, traz benefícios para o seu aprendizado (Etcheverria, 2009; Heffernan \& Ward, 2015; Sullivan \& Sheehan, 2016; Ward \& Keenan, 1999; Wielinga et al., 2019; Rodrígues \& Pérez, 2016; Winder et al., 2015; Katsuta \& Hazama, 2016; Hackett et al., 2015).

As variáveis que compõem o agrupamento das relações interpessoais do ZSC representam necessidades, atitudes, preconceitos, que o indivíduo mantém nas interações com os demais. Este agrupamento denota prejuízos no contato interpessoal e a presença de relacionamentos interpessoais permeados de sentimentos hostis (AG) em dois dos participantes do estudo (S1 e S4). Além disso, infere-se a presença de retraimento social e limitações em perceber os outros de modo real, com o predomínio de identificações com figuras parciais (cisão de objeto, e/ou com figuras mais fictícias, fantasiosas e de distanciamento do mundo real $[(\mathrm{H})$ e isolamento]) em outros dois participantes do estudo (S2 e S3). Dificuldade de interação social (Wielinga et al., 2019) e sentimentos hostis e agressivos com outras pessoas também foram reportados em outros estudos com agressores sexuais (Davis, 2017; Scortegagna \& Amparo, 2013). Estes dados sugestionam problemas nas relações interpessoais de todos os participantes.

Os indicadores que compõem a avaliação da autoimagem do ZSC podem refletir a visão que o sujeito tem sobre si com base em dados reais ou imaginários. Três dos participantes deste estudo (S1, S3, S4) revelaram percepção dos objetos como danificados (MOR), o que faz supor a presença de prejuízos na autoimagem, uma imagem pessoal desvalorizada, com traços mais negativos e disfóricos do que o habitual, e uma visão pessimista e mais negativa do meio. Em S2 e S3 pode-se sugerir a presença de alguns indicativos de sintomas depressivos. Tais descobertas apoiam os dados da literatura, os quais também indicam a existência de uma autopercepção prejudicada, com sentimentos de inferioridade e baixa autoestima presentes em criminosos sexuais (Pettersen et.al., 2016; Scortegagna \& Amparo, 2013; Sullivan \& Sheehan, 2016; Wielinga et al., 2019) e sintomas depressivos (Wielinga et al., 2019).

Os dados relativos a tradução das informações, referem-se ao grau de adaptabilidade e convencionalidade das respostas do indivíduo ao ambiente, e representam aspectos importantes de suas características de personalidade. No agrupamento da tríade cognitiva, o processamento da mediação - que se refere a precisão da interpretação dos borrões de tinta e por extensão para resolução de problemas de enfrentamento do mundo - foi o que mais se destacou entre três dos participantes (S1, S3, S4). Entre as variáveis deste aglomerado dois dos sujeitos (S3, S4) apresentaram pouca capacidade de perceber os fatos de modo objetivo, adequado, e com o mínimo de distorções subjetivas ( $\uparrow \mathrm{X}-\%)$, assim como dois deles (S1; S3) agem com pouca objetividade $(\downarrow X+\%)$.

Em comparação com a literatura relacionada, observou-se a identificação com figuras fantasiosas, assim como a distorções cognitivas na compreensão da realidade (Casarin et al., 2016). A presença de distorções cognitivas é compartilhada com estudos que mostram que alguns abusadores sexuais procuram manter uma autoimagem positiva e minimizar a percepção de danos para a vítima, o que contribui para entender seu comportamento de forma benigna (Katsuta \& Hazama, 2016; Rodrígues \& Pérez, 2016; Ward \& Keenan, 1999; Wielinga et al., 2019; Winder et al., 2015). Tais achados são compatíveis com os evidenciados no subteste percepção de faces, do Neupsilin, em que a maior parte dos sujeitos apresentou problemas cognitivos relacionados a distorções cognitivas. Muito embora essas características sejam habitualmente encontradas em criminosos sexuais elas não são exaustivas, nem estão presentes em todos os indivíduos. Alguns estudos não revelaram a existência de distorções cognitivas nesses indivíduos (Hackett et al., 2015; Nascimento, 2017), o que mostra que há diversidade entre as características de personalidade entre criminosos sexuais.

Interessante observar que o participante S3 revelou no ZSC identificações mais fantasiosas e com distorções subjetivas, enquanto no IFP-II este sujeito revelou fazer pouco uso da fantasia e imaginação. Entende-se que estes achados podem ser derivados das diferenças do modo em que estes dois testes mensuram esse construto, o ZSC é uma técnica projetiva, que acessa 
a estrutura e o funcionamento mental de maneira mais indireta. O IFP-II é um teste de autorrelato, com afirmativas que devem ser respondidas por meio de uma escala do tipo Likert e que podem ser mais controladas pelo sujeito ou também sofrer a interferência do quanto o indivíduo realmente conhece sobre si.

Os achados ratificam que o agressor espera ter seus desejos satisfeitos por alguma pessoa querida, busca apoio e proteção, atuando sexualmente contra uma criança, utilizando-a como meio de satisfazer suas necessidades (Sullivan \& Sheehan, 2016). Outro traço de personalidade presente entre os participantes deste estudo é o anseio por agir livremente e a dificuldade em controlar impulsos, como observado na Tabela 3, reafirmando resultados retratados na literatura (Arslan et al., 2016; Etcheverría, 2009; Flores-Mendoza et al., 2008; Joyal et al., 2016; Scortegagna \& Amparo, 2013; Wolff et al., 2016), além da agressividade e prazer em atacar e injuriar os outros (Casarin et al., 2016).

Observa-se semelhanças no conteúdo das narrativas no TAT dos participantes. As histórias envolvem relacionamentos e predominam o contexto de traição e ciúmes, sentimentos agressivos, danosos e possessivos. Os ambientes das narrativas são preponderantemente percebidos como conflituosos e hostis. As interações das figuras masculinas denotam comportamentos predominantes envolvidos em conflitos e violência, enquanto nas figuras femininas preponderam comportamentos passivos e tolerantes. Comportamentos agressivos e prazer em atacar e injuriar os outros são destacados em estudos prévios de Casarin et al.(2016), assim como a dificuldades em controlar impulsos (Arslan et al., 2016; Etcheverría, 2009; Flores-Mendoza et al., 2008; Joyal et al, 2016; Scortegagna \& Amparo, 2013; Wolff et al., 2016). Esses achados convergem com as características sociodemográficas que mostram que a maior parte deles havia sido encarcerado em outras circunstâncias, por brigas e desacato e com as características de personalidade encontradas nos resultados dos testes IFP-II e ZSC.

\section{Considerações Finais}

Os achados obtidos revelam características de personalidade que retratam fragilidades na constituição e no funcionamento mental, tais como: busca por afirmação pessoal, de poder e controle sobre os outros, dificuldades em lidar com impulsos, desejos de dominar e seduzir. Os dados ainda sugerem presença de vulnerabilidades no que se refere a aspectos internos e de percepção de si, indicativos de percepção distorcida da realidade e falta de habilidades sociais.

Esses fatores de risco para a violência sexual são comumente observáveis em transtornos psicológicos e amplamente reconhecidos empiricamente em criminosos sexuais de crianças. No entanto, a relação entre os fatores de risco psicodinâmicos e a violência sexual é primariamente de associação e não implica em causalidade direta.

Conhecer aspectos do funcionamento psíquico, as fragilidades e os pontos de apoio podem auxiliar no tratamento destes criminosos. Contudo, é importante destacar que esta é uma abordagem desafiadora e nem sempre o tratamento individual pode trazer resultados promissores, em virtude do sério comprometimento da saúde mental dos criminosos e dos fatores ambientais disfuncionais, presentes neste contexto. Acredita-se que os resultados sejam mais promissores na medida em que se possa desenvolver ações precoces mais abrangentes, voltadas para minimizar os riscos de danos por meio de esforços de precaução.

Nessa perspectiva preventiva abrangente, é necessário pensar nas comunidades e na sociedade como um todo. A colaboração de diferentes setores da sociedade como escolas, universidades, ambientes de trabalho, organizações não governamentais, sistemas de justiça criminal, saúde e serviço social são fundamentais, para que se possa unir esforços e prover assistência contra a violência ao indivíduo e aos envolvidos neste processo, em uma perspectiva biopsicossocial. Os programas nas escolas poderiam focar na prevenção do uso de drogas, em programas contra o abandono escolar e na inserção dos adolescentes no mundo do trabalho, bem como os relacionamentos de namoro, desde a adolescência. Além disso os programas de prevenção contra a violência poderiam contemplar as relações familiares, assistindo pais ou responsáveis pelas crianças e adolescentes. 
Por fim, há muito ainda a ser feito no sentido de mapear as características de personalidade de agressores sexuais e prover ações de cuidado. $\mathrm{O}$ seguimento de estudos poderia contemplar amostras mais abrangentes e representativas, e realizar comparações entre grupos de criminosos sexuais com diagnóstico de diversas psicopatologias.

\section{Referências}

Assini-Meytin, L. C., Fix, R. L., \& Letourneau, E. J. (2020). Child Sexual Abuse: The Need for a Perpetration Prevention Focus. Journal of Child Sexual Abuse, 29(1), 22-40. 10.1080/10538712.2019.1703232

Beier, K. M. (2018). Preventing child sexual abuse-The prevention Project Dunkelfeld. The Journal of Sexual Medicine, 15(8), 1065-1066. 10.1016/j.jsxm.2018.03.008

Casarin, J. M., Botelho, E. H. L., \& Ribeiro, R. K. S. M. (2016). Ofensores sexuais avaliados pelo Desenho da Figura Humana. Avaliação Psicológica, 15(1),6172. 10.15689/ap.2016.1501.07.

Davis, K. (2017). The Relation of Childhood Abuse Experiences to Problematic Sexual Behaviors in Male Youths: Who Have Sexually Offended? Master of Arts In Psychology, 48(7), 2149-2169. 10.1007/s10508-018-1279-3

Etcheverria, I. P. (2009). Caracterización Psicológica de un Grupo de Delincuentes Sexuales Chilenos a través del Test de Rorschach. Psykhe, 18(1),2738.10.4067/S0718-22282009000100003.

Flores-Mendoza, C. (2008). Inventário de Personalidade NEO Revisado: NEO PI-R - Manual, Vetor.

Fonseca, R. P., Salles, J. F., \& Parente, M. A. M. P. (2009). Neupsilin: Instrumento de Avaliação Neuropsicoplógica Breve, Vetor.

Franco, R. R. C., Cardoso, L. M., Villemor-Amaral, A. E. \& Primi, R. (2009). Estudos de normatização, precisão e validade. In Villemor-Amaral A. E. \& Primi, R. (Eds.), Teste de Zulliger no Sistema Compreensivo: Forma individual, Casa do Psicólogo.

Hackett, S., Masson, H., Balfe, M., \& Phillips, J. (2013).Community Reactions to Young People Who Have Sexually Abused and Their Families: A Shotgun Blast, Not a Rifle Shot. Children \& Society, 29(4), 243-254. 10.1111/chso.12030.

Heffernan, R., \& Ward, T. (2015). The conceptualization of dynamic risk factors in child sex offenders: An agency model. Aggression and Violent Behavior, 27(1), 91-108. 10.1177/1079063214561684

Joyal, C. C., Carpentier, J., \& Martin, C. (2016). Discriminant factors for adolescent sexual offending: On the usefulness of considering both victim age and sibling incest. Child Abuse \& Neglect, 54, 10-22. 10.1016/j.chiabu.2016.01.006.

Katsuta, S., \& Hazama, K. (2016). Cognitive distortions of child molesters on probation or parole in Japan. Japanese Psychological Research, 58(2), 163-174. 10.1111/jpr.12107.

Leme, I. F. A. S., Rabelo, I. S. A., \& Alves, G. A. S. (2013). IFP II - Inventário Fatorial de Personalidade. Ed. Casa do Psicólogo.

Letourneau, E. J., Schaeffer, C. M., Bradshaw, C. P., \& Feder, K. A. (2017). Preventing the onset of child sexual abuse by targeting young adolescents with universal prevention programming. Child Maltreatment, 22(2), 100-111. 10.1177/1077559517692439

Meyer, G. J., Viglione, D. J., \& Mihura, J. L. (2017). Rorschach Performance Assessment System: Administration, coding, interpretation, and technical manual. Toledo: Rorschach Performance Assessment System, LLC.

Minayo, M. C. S. (2012). Análise qualitativa: teoria, passos e fidedignidade. Ciência \& Saúde Coletiva, 17, (3), 621-626.

Murray, H. A. (2005). T.A.T. Teste de Apercepção Temática. Adaptado e ampliado (3a ed), Casa do Psicólogo.

Nascimento, A. C. G. (2017). Características dos Abusadores Sexuais. Dissertação de Mestrado, Universidade do Porto, Porto, Portugal.

Pettersen, C., Nunes, K. L., Kostiuk, N., Jung, S., \& Atlas, M. (2019). Explicit and Implicit Self-Esteem, Narcissism, and Recidivism Risk in a Sample of Men Who Have Sexually Offended Against Children. Archives of Sexual Behavior, 49(4), 1319-1332. 10.1007/s10508-019-01598-6.

Rodríguez, Z. Y. C., \& Pérez., J. I. (2016). Distorsiones cognitivas: diferencias entre abusadores sexuales, delincuentes violentos y un grupo control. Revista Criminalidad, 58(2), 141-156.

Scortegagna, S. A., \& Amparo, D. M. (2013). Avaliação psicológica de ofensores sexuais com o método de Rorschach. Avaliação Psicológica,12(3), 411-419.

Scortegagna, S. A., \& Villemor-Amaral, A. E.(2009). Autopercepção no Rorschach de vítimas de abuso sexual infantil. Psico,40(3),328-336. 10.1590/S0103863X2012000200013.

South Eastern Casa. (2017). The psycho analytic approach. Centre Against Sexual Assault e Family Violence. https://www.secasa.com.au/pages/theories-onwhy-sexual-abuse-happens/the-psychoanalytic-approach

Sullivan, J., \& Sheehan, V. (2016). What motivates sexual abusers of children? A qualitative examination of the Spiral of Sexual Abuse. Aggression and Violent Behavior, 30, 76-87. 10.1016/j.avb.2016.06.015.

Villemor-Amaral, A. E., \& Primi, R. (2009). Teste de Zulliger no sistema Compreensivo: forma individual, Casa do Psicólogo. 
Research, Society and Development, v. 10, n. 8, e34210817438, 2021

(CC BY 4.0) | ISSN 2525-3409 | DOI: http://dx.doi.org/10.33448/rsd-v10i8.17438

Wielinga, F., Margeotes, K., \& Olver, M. (2019). Clinical and risk relevance of intimacy and loneliness in a treated sample of men who have offended sexually. Journal of Sexual Agression, 1-18. 10.1080/13552600.2019.1698778.

Ward, T., \& Keenan, T. (1999). Child molesters' implicit theories. Journal of Interpersonal Violence, 14, 821-838. 10.1177/088626099014008003.

Winder, B., Gough, B., \& Seymour-Smith, S. (2015). Stumbling into sexual crime: the passive perpetrator in accounts by male internet sex offenders. Archives of Sexual Behavior, 44(1),167-80. 10.1007/s10508-014-0302-

Yin, R. K. (2015). Estudo de caso: planejamento e métodos. (5a ed.), Bookman. 